\title{
D- and E-region effects in the auroral zone during a moderately active 24-h period in July 2005
}

\author{
J. K. Hargreaves ${ }^{1,2}$, M. J. Birch ${ }^{1,3}$, and B. J. I. Bromage ${ }^{1}$ \\ ${ }^{1}$ Centre for Astrophysics, University of Central Lancashire, Preston PR1 2HE, UK \\ ${ }^{2}$ Dept. of Communication Systems, University of Lancaster, Bailrigg, Lancaster LA1 8LL, UK \\ ${ }^{3}$ Dept. of Computing, University of Central Lancashire, Preston PR1 2HE, UK
}

Received: 4 July 2006 - Revised: 9 July 2007 - Accepted: 1 August 2007 - Published: 29 August 2007

\begin{abstract}
The effects of energetic electron precipitation into the auroral region at a time of enhanced solar wind have been investigated during a continuous period of $24 \mathrm{~h}$, using the European Incoherent Scatter (EISCAT) radar, an imaging riometer, and particle measurements on an orbiting satellite. The relative effects in the $\mathrm{E}$ region $(120 \mathrm{~km})$ and $\mathrm{D}$ region $(90 \mathrm{~km})$ are found to vary during the day, consistent with a gradual hardening of the incoming electron spectrum from pre-midnight to morning. Whereas the night spectra are single peaked, the daytime spectra are found to be double peaked, suggesting the presence of two distinct populations.

A comparison between the radiowave absorption observed with the riometer and values estimated from the radar data shows generally good agreement, but with some discrepancies suggesting the occurrence of some small-scale features. The height and thickness of the absorbing region are estimated. Two periods of enhanced precipitation and the related radio absorption, one near magnetic midnight and one in the early morning, are studied in detail, including their horizontal structure and movement of the absorption patches.

A sharp reduction of electron flux recorded on a POES satellite is related to the edge of an absorption region delineated by the imaging riometer. The observed particle flux is compared with a value deduced from the radar data during the overpass, and found to be in general agreement.
\end{abstract}

Keywords. Ionosphere (Auroral ionosphere; Ionospheric disturbances; Particle precipitation)

\section{Introduction}

The opportunity for this study arose from a more general investigation into the terrestrial effects of enhanced solar wind

Correspondence to: J. K. Hargreaves

(j.hargreaves@lancaster.ac.uk) related to the meridian passage of a coronal hole in JuneJuly 2005, further results of which will be reported elsewhere. A large coronal hole extending from the solar north pole to the equator had been observed over several solar rotations, and, using the history and EUV observations made with the SOHO satellite, together with solar wind data from ACE (both at the L1 point), a prediction was made for the time of its meridian crossing at the end of June and the consequent solar wind enhancement at the magnetosphere. Arrangements were made for the EISCAT radars to be operated at a time when ionospheric effects attributable to the crossing might be observed.

The prediction proved to be accurate. The radar was operated from 10:00 UT on 1 July. The solar wind began to increase at 13:03 UT at Wind and at 13:33 UT at ACE on that day, and reached a peak velocity exceeding $600 \mathrm{~km} / \mathrm{s}$ at 23:00 UT, thereafter declining gradually over several days. There was no coronal mass ejection (CME) accompanying this event. Terrestrial magnetometers recorded a sudden commencement at 14:12 UT, which was followed by moderate activity lasting several hours. The $K_{p}$ index was in the range 4- to 4+ between 15:00 UT on 1 July and 03:00 UT on 2 July, and the auroral electrojet index AE was enhanced over the same period, peaking at almost $1000 \mathrm{nT}$.

The present communication is concerned with the development and properties of energetic electron precipitation and its consequences observed over Northern Scandinavia during a continuous period of $24 \mathrm{~h}$. Topics of particular interest are the relative magnitudes of effects in the ionospheric $\mathrm{E}$ and $\mathrm{D}$ regions, the spectra of the incoming particles, and related radio-absorption phenomena.

\section{Observations}

Several of the EISCAT radars in northern Scandinavia were operated to cover the period from 10:00 UT on 1 July until

Published by Copernicus Publications on behalf of the European Geosciences Union. 

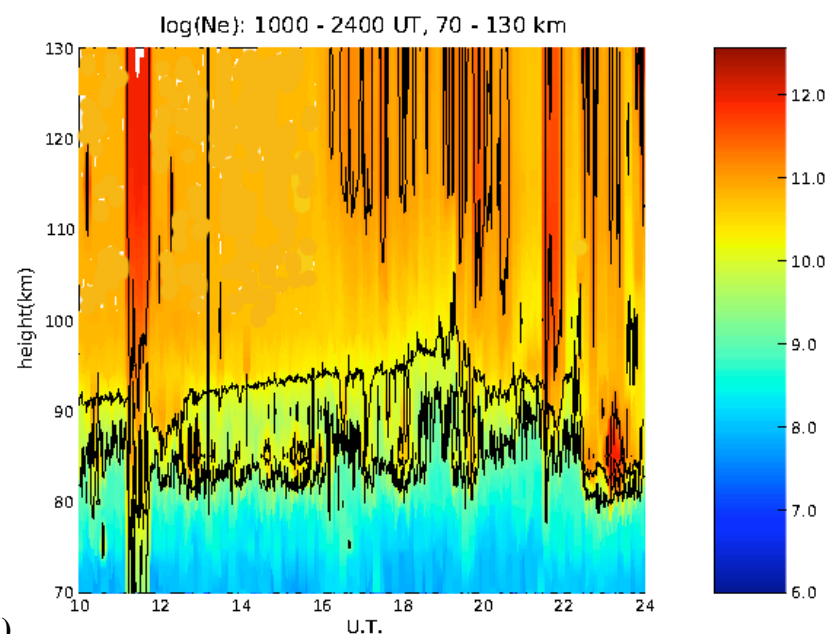

(a)
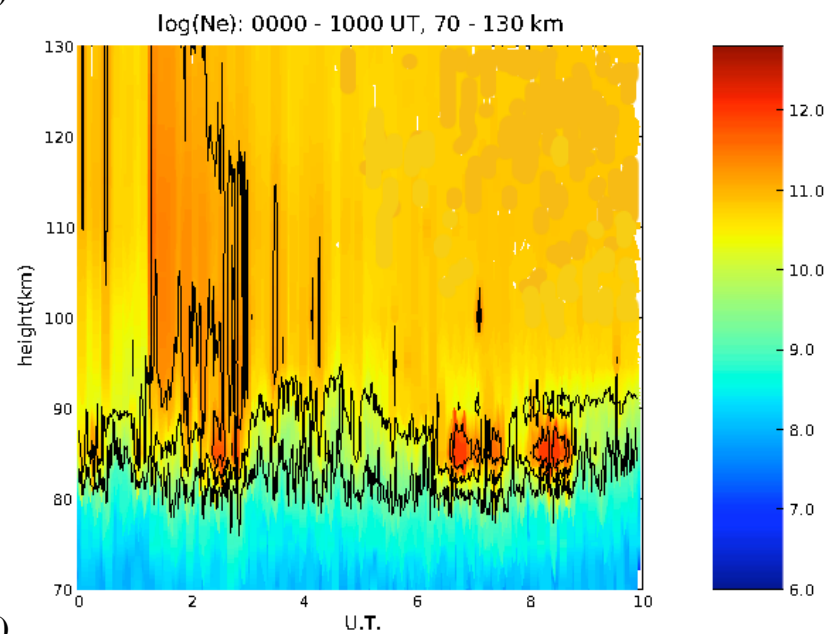

(b)

Fig. 1. D-region electron density observed with the EISCAT VHF radar on 1 and 2 July 2005. The time resolution is about a minute. Contours are marked at $10^{9}, 10^{10}$ and $10^{11} \mathrm{~m}^{-3}$.

10:00 UT on 2 July. The present paper uses results from the $224 \mathrm{MHz}$ VHF system at Tromsö $\left(69.59^{\circ} \mathrm{N}, 19.23^{\circ} \mathrm{E}\right.$, $\mathrm{L}=6.1$ ), which was pointed vertically and ran a program (arc_dlayer_v) designed for D- and E-region observation and covering the altitude range $60-140 \mathrm{~km}$. Due to its longitude, $2 \mathrm{~h} 20$ min should be added to Universal Times to get the Local Magnetic Time at EISCAT.

The imaging riometer system at Kilpisjärvi $\left(69.05^{\circ} \mathrm{N}\right.$, $20.79^{\circ} \mathrm{W}, \mathrm{L}=5.9$ ) operates continuously and measures the absorption of the cosmic radio noise at $38.2 \mathrm{MHz}$ (Detrick and Rosenberg, 1990; Browne et al., 1995). Having 49 beams it provides information on the spatial and temporal variations in the D region and covers in all some $240 \mathrm{~km}$ north-south and east-west, assuming the absorption is centred at altitude $90 \mathrm{~km}$. In the present study it is used to indicate D-region consequences of precipitated energetic electrons.
Table 1. Reduction of electron density to $5-\mathrm{km}$ steps.

\begin{tabular}{cc}
\hline $\begin{array}{c}\text { Nominal height } \\
(\mathrm{km})\end{array}$ & $\begin{array}{c}\text { Range of values } \\
\text { averaged }(\mathrm{km})\end{array}$ \\
\hline $60-100$ & \pm 1 \\
105 & \pm 2.5 \\
$110-115$ & \pm 1.5 \\
120 & \pm 2 \\
$125-130$ & \pm 1.5
\end{tabular}

The POES series of NOAA satellites are in sunsynchronous orbits at altitude $850 \mathrm{~km}$ (Evans and Greer, 2004). Their instrumentation includes electron telescopes pointing $9^{\circ}$ and $90^{\circ}$ from the vertical direction. For convenience these are called the $0^{\circ}$ and $90^{\circ}$ telescopes. At auroral latitudes they are centred about $17^{\circ}$ and $102^{\circ}$ with respect to the magnetic field direction. Their reception cones have half-angles of width $15^{\circ}$. The data from each detector are analysed to give the counting rate in three energy ranges: $30-2500 \mathrm{keV}, 100-2500 \mathrm{keV}$ and $300-2500 \mathrm{keV}$. The count rate may be converted to the flux in $\mathrm{cm}^{-2} \mathrm{~s}^{-1} \mathrm{sr}^{-1}$ by multiplying it by a factor of 100 , which represents the geometric factor of the instrument. The four satellites are at different local times, thus providing some longitude coverage; the number of measurements at a given location is also limited (and not always in a predictable way) by the orbital period of $102 \mathrm{~min}$. The particle measurements will be compared with ionospheric behaviour during an overflight of Scandinavia.

\section{Electron densities in the D- and E-regions over Tromsö}

\subsection{Overview}

Figure 1 illustrates the magnitudes and variations of D- and E-region electron density as determined by the EISCAT VHF radar during the periods 10:00-24:00 UT on 1 July and 00:00-10:00 UT on 2 July. The time resolution is $64 \mathrm{~s}$, and the radar returns were reduced to the stated altitudes by averaging all values within a specified height range, according to Table 1 . The plots include contours at $10^{9}, 10^{10}$, and $10^{11} \mathrm{~m}^{-3}$.

Significant activity began just before 16:00 UT on 1 July and it continued until about 08:00 UT on 2 July. There are several features that should be ignored. The apparent enhancement between 11:15 and 11:45 UT on 1 July is almost certainly due to a malfunction (I. W. McCrea, private communication). Then, there occur intermittently throughout the period of observation intense echoes from about $85 \mathrm{~km}$ altitude which are "polar mesosphere summer echoes (PMSE)" due to thin scattering regions in the medium rather than enhanced electron density. Overall, the enhancements due to 
geophysical activity are moderate rather than strong. We shall concentrate on the two periods of greatest disturbance, one starting about 21:30 UT on 1 July and the other running from about 01:20 to 03:00 UT on 2 July.

We note in passing that the period 21:30 to 03:00 UT, which was the time of greatest geophysical activity, corresponded with an enhancement in the speed of the solar wind. At 20:20 UT on 1 July the solar-wind speed at the Wind satellite (1.66 million $\mathrm{km}$ from the centre of the Earth) was $470 \mathrm{~km} / \mathrm{s}$ but it then began to increase sharply. Allowing 57 min for propagation, the increase would have reached the magnetopause about 21:17 UT, which was shortly before the onset of the observed evening event. The solar-wind speed peaked at $650 \mathrm{~km} / \mathrm{s}$, and by 03:00 UT on 2 July had fallen to $550 \mathrm{~km} / \mathrm{s}$, remaining about that value until after 08:00. During the same period the solar wind had a significant eastward component of $90 \mathrm{~km} / \mathrm{s}$. There were no remarkable changes in the interplanetary magnetic field in this period, though a sector boundary went by (with some oscillations) between 08:40 and 14:40 UT on 1 July.

\subsection{Noise levels}

At the lowest altitudes $(60-70 \mathrm{~km})$ the electron-density data are noisy, with large variations from point to point and little evidence of sustained enhancements such as are observed at the greater heights. We assume that this represents the noise level of the experiment, and it is found that at 60 and $65 \mathrm{~km}$ the statistical distributions of "electron density" are close to the Rayleigh form with standard deviation $2.85 \times 10^{7}$ at $60 \mathrm{~km}$ and $3.60 \times 10^{7}$ at $65 \mathrm{~km}$.

Because of the range correction in processing the radar data, the noise expressed as electron density should vary with the square of the range. Taking an average of the values from 60 and $65 \mathrm{~km}$, it is estimated that at the higher levels, where signal dominates, the errors due to noise will be such that $90 \%$ of values will be within $11.6 \times 10^{3}(\mathrm{R}(\mathrm{km}))^{2} \mathrm{~m}^{-3}$ of the true value. This figure varies with height between $8 \times 10^{7} \mathrm{~m}^{-3}$ at $85 \mathrm{~km}$ and $2 \times 10^{8} \mathrm{~m}^{-3}$ at $130 \mathrm{~km}$. Specifically, the error should be less than $10 \%$ for electron densities of at least $8 \times 10^{8} \mathrm{~m}^{-3}$ at $85 \mathrm{~km}$, or at least $2 \times 10^{9} \mathrm{~m}^{-3}$ at $130 \mathrm{~km}$.

\subsection{E- and D-region comparison}

The $120 \mathrm{~km}$ level may be reached by electrons having energy of at least $1-2 \mathrm{keV}$. It is typical of the E region and the site of the luminous aurora. The $90 \mathrm{~km}$ level in the D region is the one most affected by auroral radio absorption and is only reached by electrons with energies of about $25 \mathrm{keV}$ or more, the maximum ion production rate at that height being due to electrons of about $50 \mathrm{keV}$.

Figure 2 illustrates the relative E- and D-region activity at times throughout the observing period. The increase of $120-\mathrm{km}$ electron density at 16:00 UT probably represents the
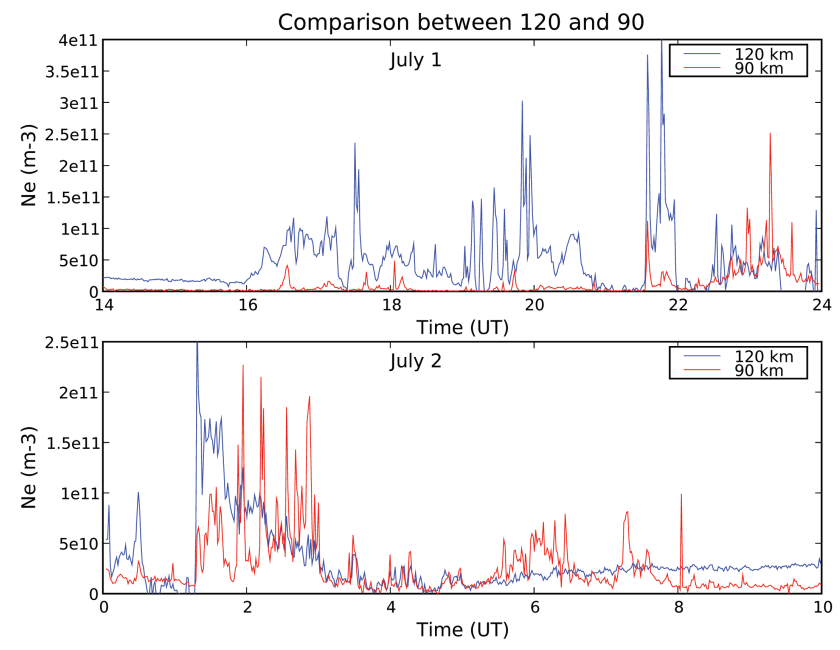

Fig. 2. Comparison between E- $(120 \mathrm{~km})$ and D- $(90 \mathrm{~km})$ region activity.

onset of ionospheric activity resulting from the solar wind enhancement, and the lack of D-region response indicates that this activity in the afternoon sector was due to soft precipitation. Significant D-region activity such as may be detected with a riometer did not begin until shortly before local magnetic midnight $(\sim 22: 00 \mathrm{UT})$, which is not atypical for the commencement of night-time absorption activity. The precipitation continued to harden into the morning sector, and about 03:00 and 06:00 UT there were instances where the electron density in the $\mathrm{D}$ region actually exceeded that in region $\mathrm{E}$.

Based on the features in Fig. 2 several electron-density profiles (Fig. 3a) have been selected for more detailed study. The profiles shown have been corrected for a contribution from solar EUV radiation when the E region is illuminated. For heights above $100 \mathrm{~km}$, plots of electron density against time show a smooth variation during undisturbed periods (i.e. before 16:00 UT on 1 July and after 04:00 UT on 2 July) and a minimum level consistent with the trend during the activity. The background due to EUV was estimated from that trend.

There are, of course, short term variations, but it can be seen overall that as time progresses the profiles move lower, with the D-region contribution increasing relative to the $\mathrm{E}$ region. Thus:

1. $16: 34$ UT: In this feature the D-region $(90 \mathrm{~km})$ was weak relative to the E-region $(120 \mathrm{~km})$, indicating a soft spectrum. The enhancement at $120 \mathrm{~km}$ was about 20 times that at $90 \mathrm{~km}$.

2. 21:48 UT: This feature was a short-duration enhancement occurring close to magnetic midnight at EISCAT, following a spike and within a night-time auroral absorption event. The E-region enhancement was again more prominent than that at $90 \mathrm{~km}$ (by about a factor 


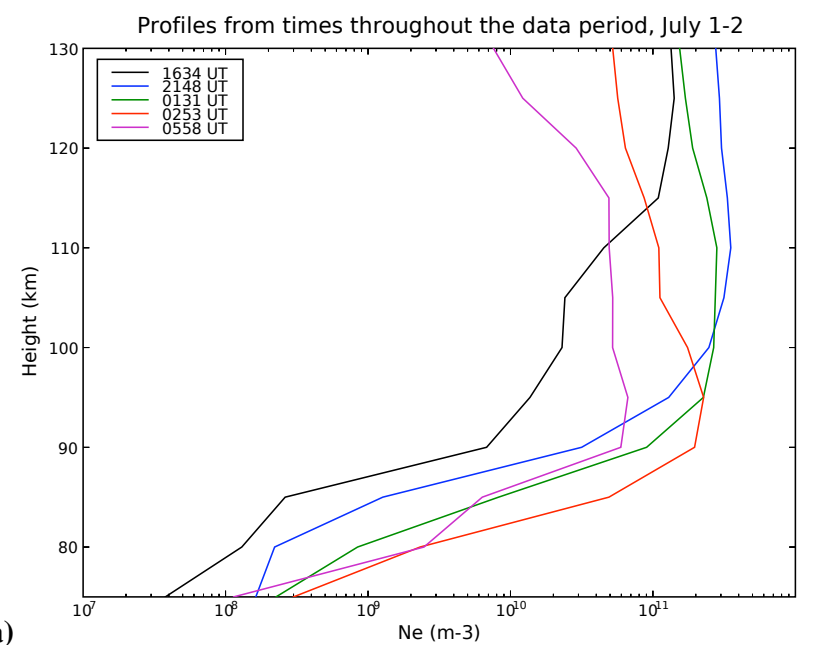

(a)

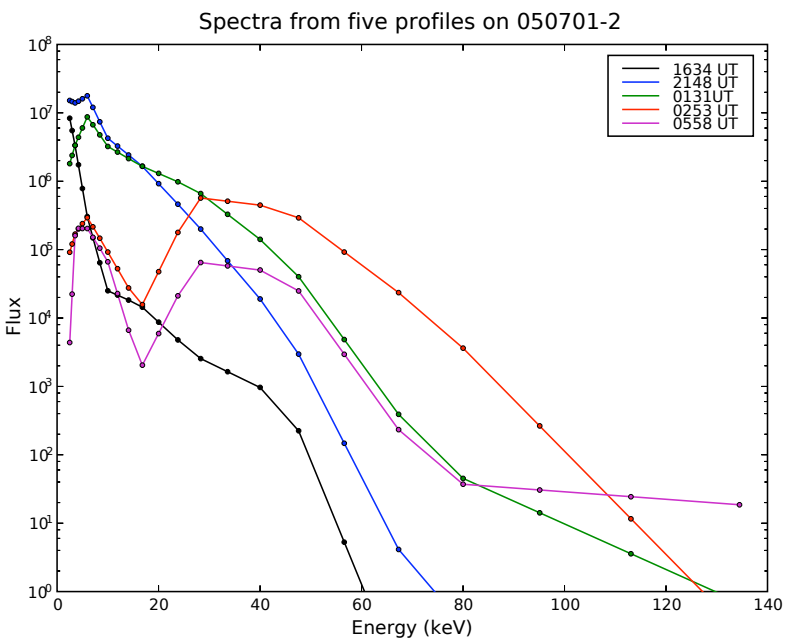

Fig. 3. (a) A selection of electron-density profiles covering the observing period on 1-2 July. The profiles have been corrected for the estimated contribution from solar EUV radiation, which is significant only in the E region and at the smaller electron-density values. (b) Energetic electron spectra estimated from the above profiles. The flux is in units of electrons $\mathrm{cm}^{-2} \mathrm{~s}^{-1} \mathrm{sr}^{-1} \mathrm{keV}^{-1}$.

of 10), again indicating a soft spectrum. The electrondensity profile (Fig. 3a) shows the maximum to be lower than it was at 16:34.

3. 01:31 UT: This enhancement occurs near the beginning of the extended morning event and the electron density at $120 \mathrm{~km}$ is twice that at $90 \mathrm{~km}$. This event is harder than those above.

4. 02:53 UT: This is the last $90 \mathrm{~km}$ peak of the morning event. The electron density is now larger at $90 \mathrm{~km}$ than at $120 \mathrm{~km}$, and there has been a marked change of spectrum within $1.5 \mathrm{~h}$, with a clear trend in the $90 \mathrm{~km} / 120 \mathrm{~km}$ electron-density ratio. Superimposed throughout that period are short D-region enhancements

(a)

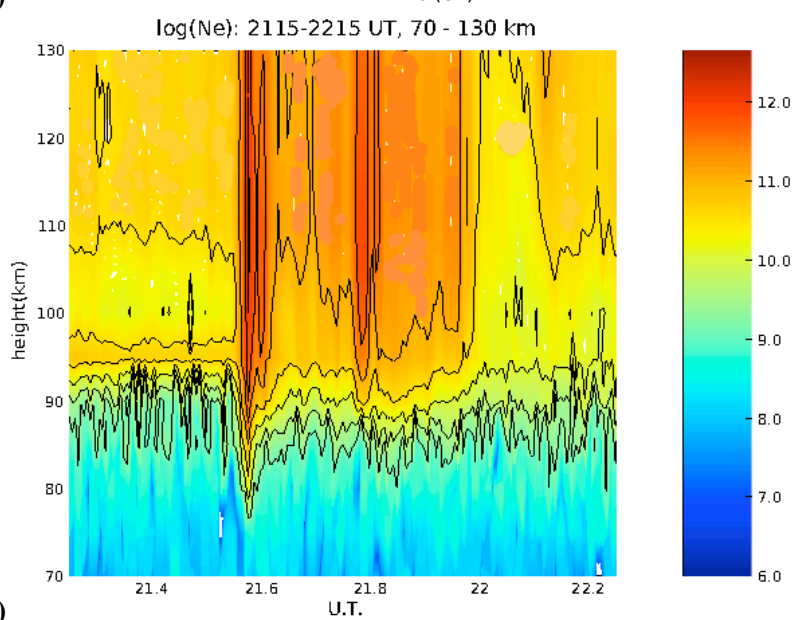

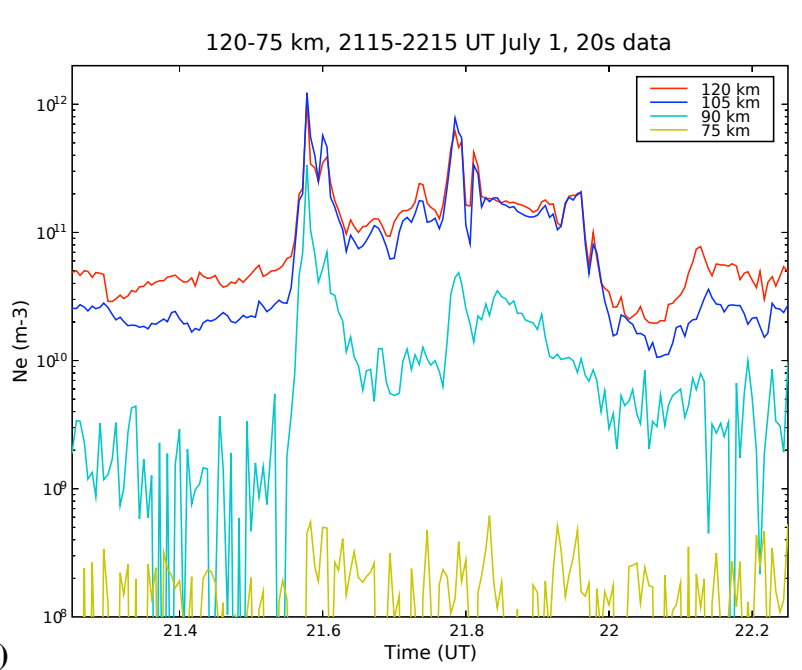

Fig. 4. Spike and precipitation event on the evening of 1 July covering 21:15-22:15 UT (21.25-22.25 UT). The time resolution is $20 \mathrm{~s}$. The upper panel plots the electron density every $15 \mathrm{~km}$ between 75 and $120 \mathrm{~km}$. In the lower panel there are two contours to a factor of ten in electron density, starting at $10^{9} \mathrm{~m}^{-3}$.

without, or with only weak, E-region peaks; these correspond with bursts of auroral absorption observed with the riometer.

5. At 05:58 UT: This morning event is weak at $90 \mathrm{~km}$ but hardly visible at all at $120 \mathrm{~km}$, and it looks like the hardest spectrum of the selection. The electron-density profile again peaks at relatively low altitude, where there has been a significant enhancement. There is not much effect in the E-region, the electron density seen in Fig. 2 being mainly due to the EUV contribution, with consequently a large E-region correction on Fig. $3 a$.

Two other candidates (at 23:20 and 07:20 UT) were rejected because some of the readings at the lower altitudes were affected by PMSE. 


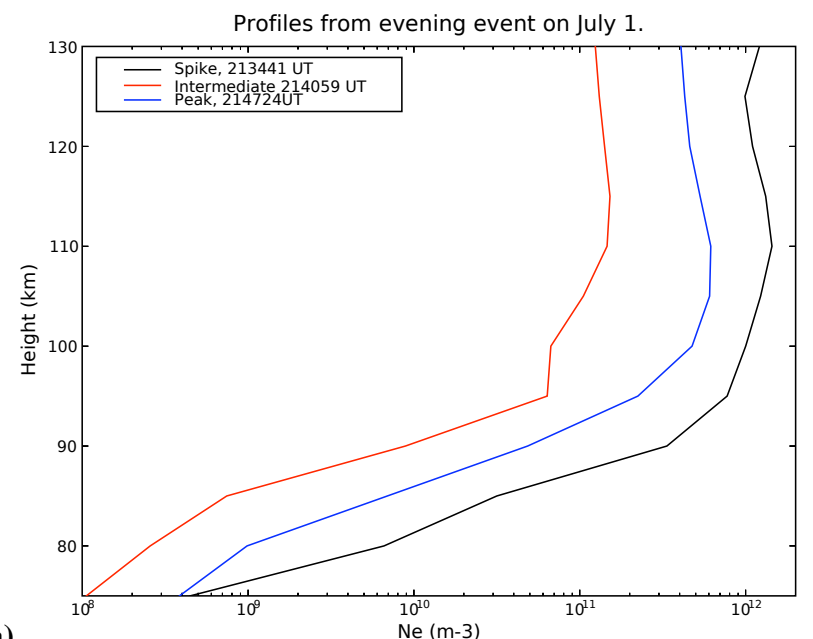

(a)

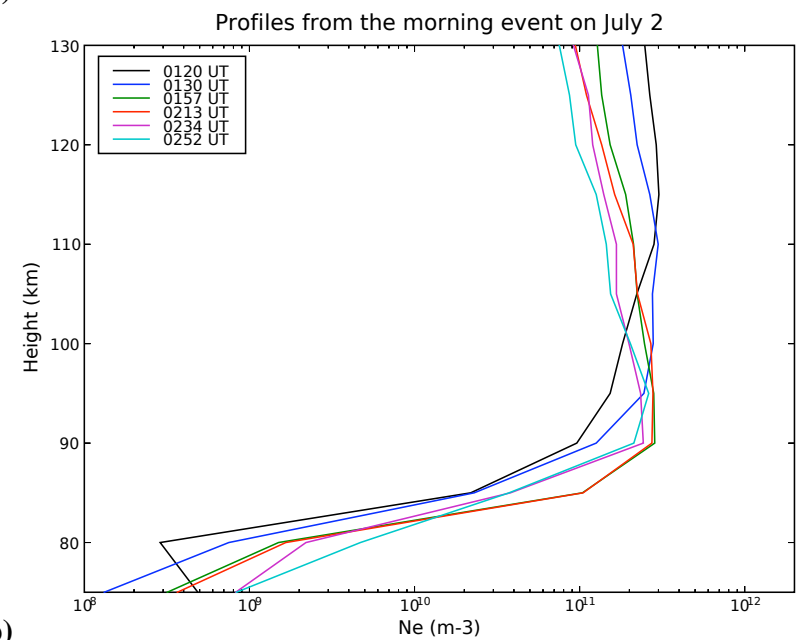

(b)

Fig. 5. (a) Profiles from the evening event on 1 July. (b) Profiles from the morning event on July 2, corrected for solar EUV contributions.

\subsection{Deduced spectra}

These five electron-density profiles have been inverted using the method described by Hargreaves and Devlin (1990) to give estimates of the incoming energetic-electron spectrum (Fig. 3b). The method entails some assumptions and uncertainties, so ultimate precision cannot be expected. It depends on atmospheric models which may be inaccurate, and there are assumptions about the pitch-angle distribution of the incoming particles which generally is not known. But the greatest scope for error arises with the height profile of the effective recombination coefficient for electrons in the D and $\mathrm{E}$ regions. In the present instance the lower values are taken from recent determinations (Hargreaves, 2005; Hargreaves and Birch, 2005), and the upper ones from Gledhill (1986), with interpolation between the two sets at 90 and $95 \mathrm{~km}$. However, tests have indicated that reasonable vari-

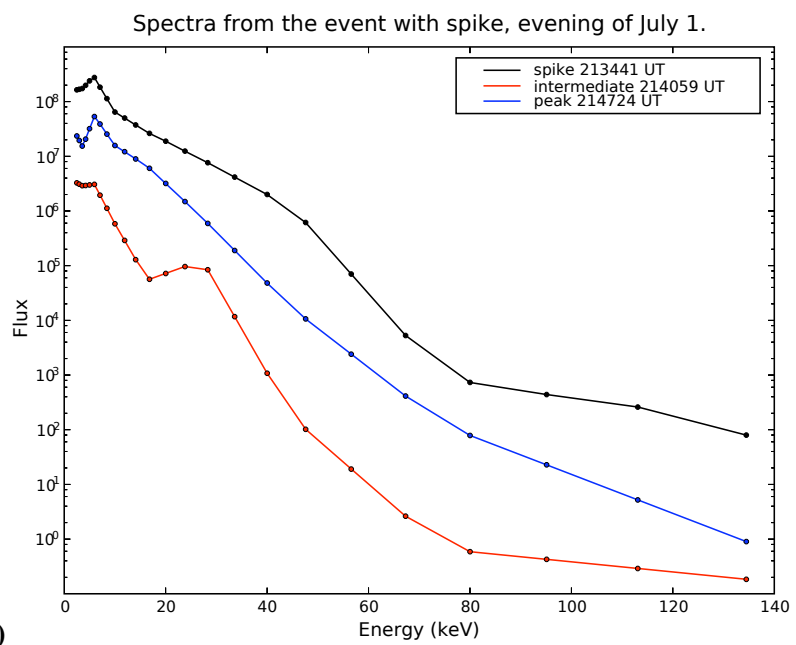

(a)

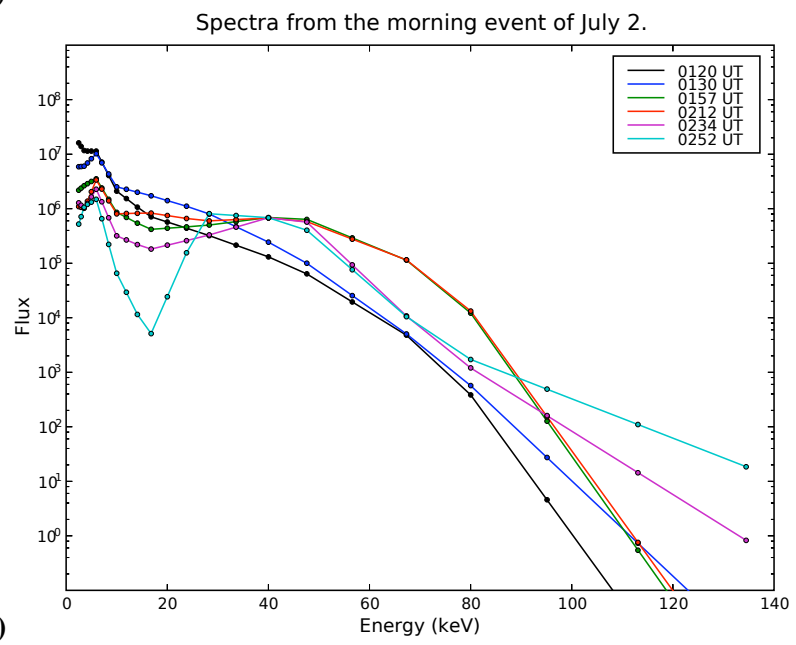

Fig. 6. (a) Spectra deduced from the profiles of Fig. 5a. (b) Spectra deduced from the profiles of Fig. 5b.

ations of effective recombination coefficient do not change the overall character of the spectrum. Inter-comparisons are therefore likely to be valid.

A marked change of character is evident in Fig. 3b, in that the spectra at 02:53 and 05:58 UT are double peaked, each at about $7 \mathrm{keV}$ and $40 \mathrm{keV}$. The earlier spectra, at 21:48 and 01:31 UT, are single peaked, the slope at higher energies being very approximately exponential (with characteristic energies $4.3 \mathrm{keV}$ and $6.7 \mathrm{keV}$, respectively). Such an approximation is plainly not useful for the double peaked spectra, except perhaps over a very limited range of energy. The spectrum for 16:34 UT is exponential between 2.5 and $10 \mathrm{keV}$ (with characteristic energy $1.2 \mathrm{keV}-$ i.e. very soft), though there appears to be a small flux of harder particles in addition.

In summary, we find a tendency on 1-2 July for the incoming electron spectrum to harden progressively from the evening through to the morning. The form of the spectrum 

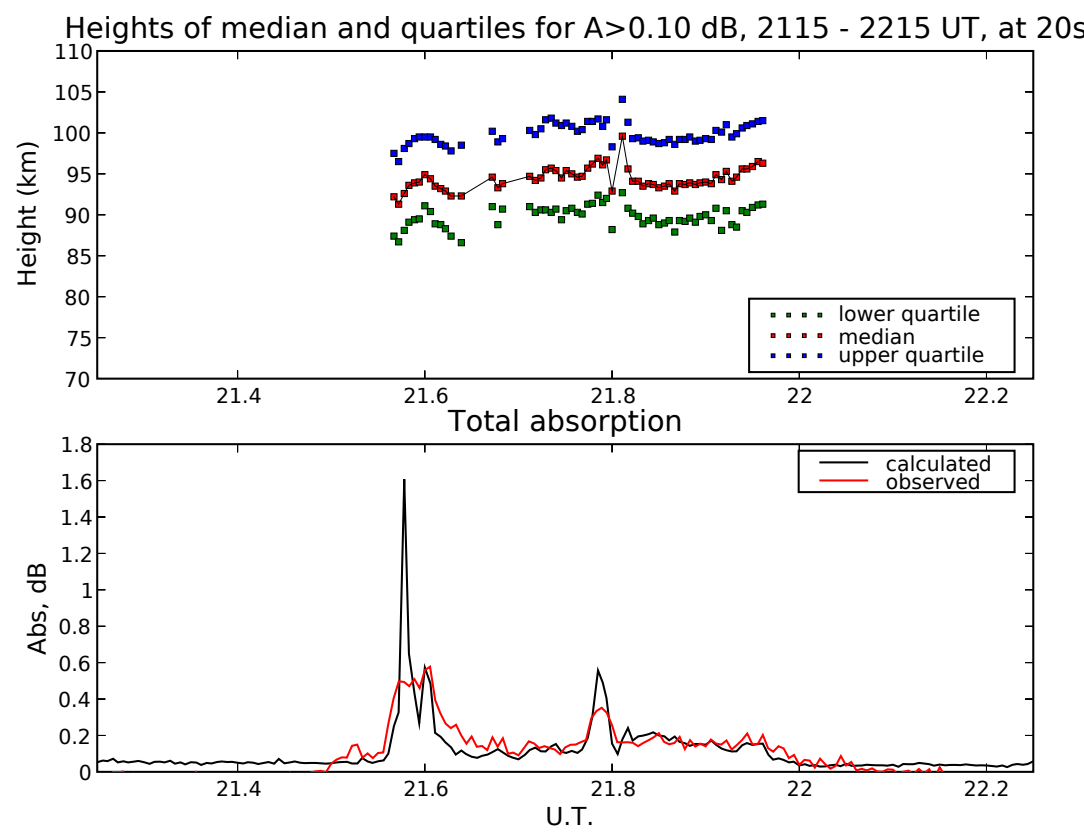

Fig. 7. Above: Heights of medians and quartiles for the absorbing region during the evening event of 1 July. Below: Total $38.2 \mathrm{MHz}$, calculated and observed.

changes character from approximately exponential to a form that is relatively enhanced at several tens of $\mathrm{keV}$ and may be double peaked. The resulting profiles in the lower ionosphere show the D-region effect increasing relative to that in the $\mathrm{E}$ region, with the maximum moving to lower altitude. The double peaked spectra may indicate the presence of two populations of energetic electrons.

\section{The night-time event}

The strongest D- and E-region disturbance of 1 July was an enhancement that started about 21:30 UT and lasted for about half an hour (Fig. 4). In the initial spike the electron density exceeded $10^{12} \mathrm{~m}^{-3}$ in the $\mathrm{E}$ region for a short time. The spike was followed by a more slowly varying enhancement, giving the appearance typical of a substorm event (though see later!). Another short-duration feature occurred halfway through the event.

Vertical profiles during the spike, during the short-duration feature, and at a time intermediate between the two are shown in Fig. 5a. The profiles are similar in shape, peaking in the E region, though without much variation between 100 and $130 \mathrm{~km}$. The three derived spectra (Fig. 6a) display considerable difference in intensity, the spike fluxes being at least 100 times those at the intermediate point, but they all have approximately exponential forms between 10 and $80 \mathrm{keV}$ and their characteristic energies are rather similar, at $6.7 \mathrm{keV}$ for the spike, $5.6 \mathrm{keV}$ for the peak and $4.9 \mathrm{keV}$ for the intermediate point. The last spectrum includes a minor peak at 20 $35 \mathrm{keV}$ which may or may not be significant.
The radio absorption at $38.2 \mathrm{MHz}$ may be calculated from the electron-density profile by applying the appropriate values of the height-dependent specific absorption coefficient (defined as the absorption per $\mathrm{km}$ due to unit electron density - Parthasarathy and Berkey, 1965; Hargreaves, 1980). Figure 7 shows the height of the absorbing layer in terms of the median and quartiles. During this period the absorbing layer was centred about $95 \mathrm{~km}$, and the width of the layer was such that half the absorption occurred over about $10 \mathrm{~km}$ of altitude. The total absorption calculated is also compared in Fig. 7 with that observed in the beam of the Kilpisjärvi imaging riometer which most nearly intersected the D region over the radar (which was pointed vertically). There is tolerable agreement except that the initial spike as observed was considerably smaller than the calculated value. The difference could mean that the feature in question was of small horizontal extent. The radar beam is only 1 by $3 \mathrm{~km}$ at $90 \mathrm{~km}$ altitude, whereas the riometer beam covers some 50 by $25 \mathrm{~km}$ between half-power points. A spatially confined feature could be clearly observed by the radar but register only weakly on the riometer if it failed to fill the relevant beam.

We can learn more about the nature of these features from the absorption images constructed from the imaging riometer. The panels in Fig. 8 each cover $240 \mathrm{~km}$ north-south and east-west at an assumed height of $90 \mathrm{~km}$, and they are presented as if viewed from above. A total period of $3 \mathrm{~min}$ including the initial spike event at 21:34 UT (21.57 UT) is covered at $20 \mathrm{~s}$ resolution. The event is strongest in the southern part of the field of view, and the maximum traverses the field of view from west to east in just over a minute (velocity 
IRIS absorption images (plan)

2005-07-01 21:33:00 - 21:36:00 UT @ 20 s res.

Kilpisjärvi, Finland $\left(69.05^{\circ} \mathrm{N}, 20.79^{\circ} \mathrm{E}\right)$
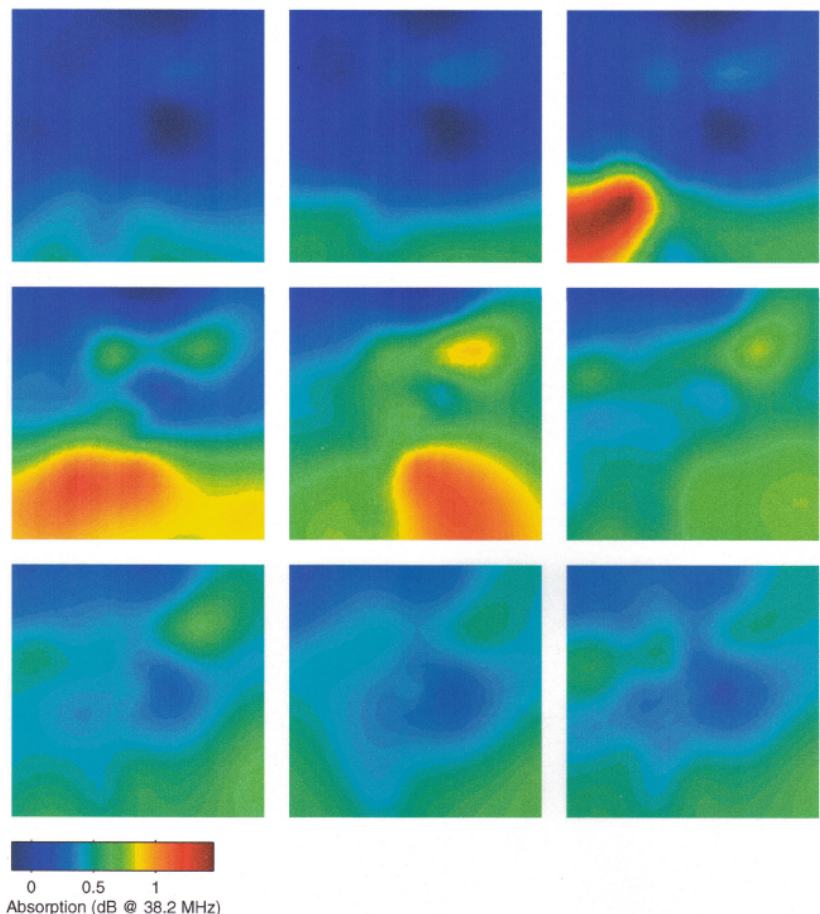

Fig. 8. Motion of the evening spike as observed by the Kilpisjärvi imaging riometer. These images are based on interpolation between the $90-\mathrm{km}$ intersections of the 49 beams.

estimated at $2.9 \mathrm{~km} / \mathrm{s})$. This speed and duration are typical of spike events at the beginning of substorms (Hargreaves et al., 1997), but the direction of motion is not. The most characteristic motion at the beginning of a substorm is poleward. In this case there is some poleward progression which then ceases as the event decays - all of which suggests that this feature may be related instead to a "pseudo-breakup" (Akasofu, 1964). On these images the radar intersection is halfway between the centre and the top left corner. The spike which the radar observes appears to be part of the poleward extension of the main peak, but its motion is clearly eastward.

Maps over the period of the peak at 21:47 UT (21.78 UT) indicate a local intensification within an ill-defined pattern (composed mainly of weak absorption), but with a slow equatorward drift (velocity about $160 \mathrm{~m} / \mathrm{s}$ ). Slow equatorward drift is not atypical in the later part of a night-time absorption event (Hargreaves, 1974).

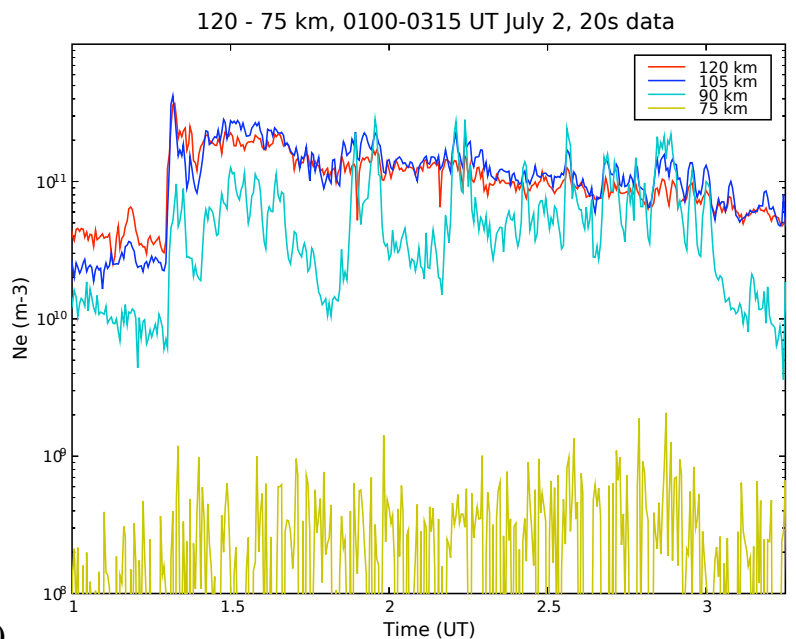

(a)

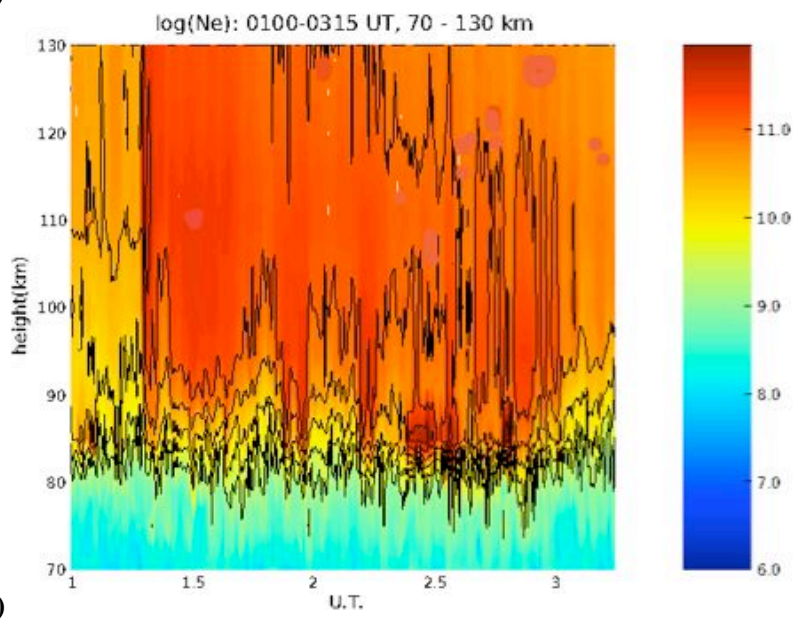

Fig. 9. Electron density at $15-\mathrm{km}$ intervals and contour map from 01:00-03:15 UT on 2 July at $20 \mathrm{~s}$ time resolution.

\section{The early-morning event}

\subsection{Introduction}

The properties and significance of the period of activity lasting almost $2 \mathrm{~h}$ from about 01:15 UT (01.25 UT) on 2 July have been explored in a similar fashion. This period (Fig. 9), which is several hours after local magnetic midnight, starts with a sharp onset after which the E-region electron densities decline steadily with only minor fluctuations. By contrast, the $\mathrm{D}$ region (particularly at 85,90 and $95 \mathrm{~km}$ ) shows considerable structure, some variations being more than a factor of ten. (From Sect. 3.2, variations less than $2.10^{8}$ at $130 \mathrm{~km}$ or $8.10^{7}$ at $85 \mathrm{~km}$ should be disregarded as experiment noise.) The effects are seen most clearly at the lower edge of the region, whereas there is relatively little height variation within the E region between, say, 100 and $120 \mathrm{~km}$ (Fig. 9b). 

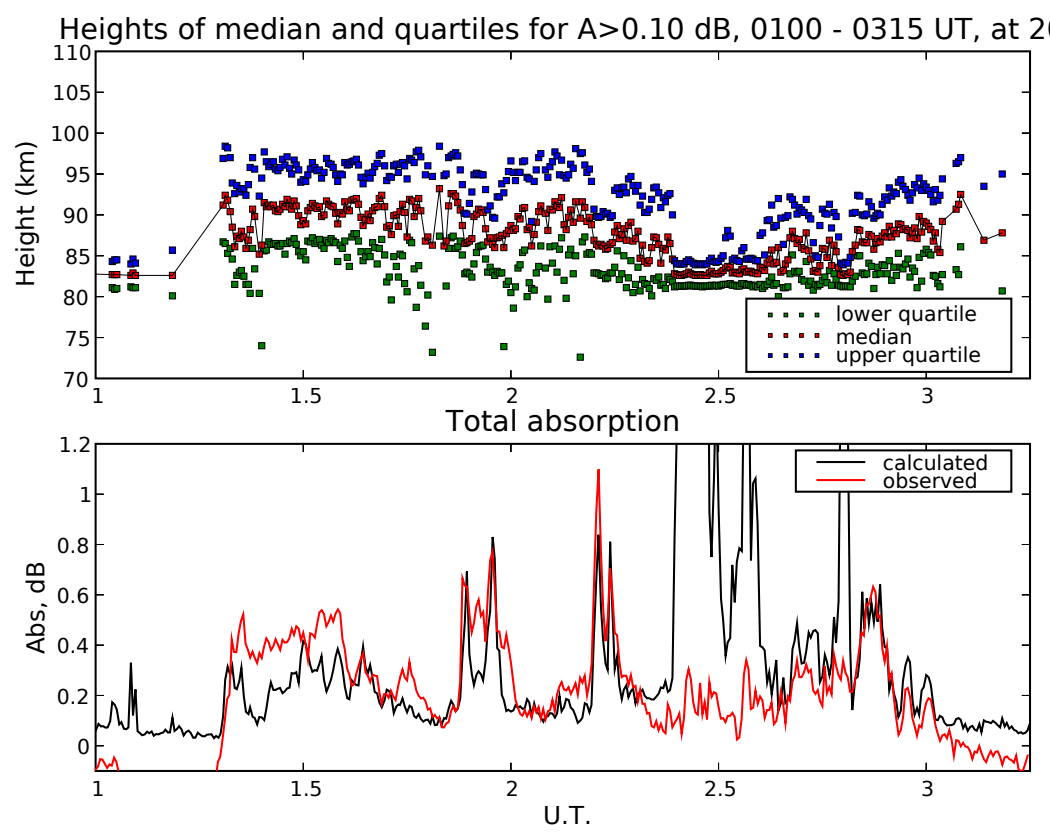

Fig. 10. The absorption layer for 01:00-03:15 UT (01.00-03.25 UT) on 2 July. The upper panel shows the calculated median and quartiles, and the lower one compares the calculated $38.2 \mathrm{MHz}$ absorption with that observed with the Kilpisjärvi imaging riometer.

\subsection{The absorption layer}

The computed absorption layer (Fig. 10) is somewhat lower than during the evening event, with the median generally near $90 \mathrm{~km}$ but also sometimes as low as $85 \mathrm{~km}$. The thickness between quartiles is still about $10 \mathrm{~km}$. Between about 02:20 and 02:40 UT (02.33-02.67 UT) the layer appears to be very narrow, but this is an artifact caused by intense returns from PMSE.

The lower panel of Fig. 10 compares the calculated $38.2 \mathrm{MHz}$ absorption with that observed with the beam of the Kilpisjärvi imaging riometer which intersects the 90$\mathrm{km}$ level over the radar. The smaller values of absorption are comparable with the uncertainty of the quiet-day curve (QDC), and $0.1 \mathrm{~dB}$ has been subtracted from the observed values. Before 01:20 UT (01.33 UT) there are some negative values which are due to an error in the QDC, and until about 01:40 UT (01.67 UT) the absorption values may be somewhat too high from the same cause. Overall, and considering that we are dealing with fairly small values, the observed and calculated absorption patterns agree as well as can be expected. We again see a tendency for the computed values to show sharper structure than those observed with the imaging riometer, and it is suggested that the cause may be the difference in spatial resolution between the two systems involved, the riometer beam covering almost $1000 \mathrm{~km}^{2}$, but the radar beam only $3 \mathrm{~km}^{2}$. Indeed, the argument could be reversed to assert that the closeness of the agreement indicates that the absorption is relatively lacking in structure on scales smaller than about $30 \mathrm{~km}$.

\subsection{Profiles and spectra}

Figures $5 \mathrm{~b}$ and $6 \mathrm{~b}$ show electron-density profiles and spectra deduced therefrom at 6 maxima during the morning event. The profiles differ in character from those derived for the evening event (Fig. 5a), peaking lower and having a sharper underside. The corresponding spectra have relatively greater flux in the $20-80 \mathrm{keV}$ range. Some of the spectra are essentially flat up to about $60 \mathrm{keV}$, and by no stretch of the imagination could they be described by simple forms such as exponential or power-law. There is also a progressive change during the event, the mid-range contribution being relatively larger in the later peaks than in the earlier ones.

\subsection{Dynamics}

The absorption peaks within the morning events show generally eastward movements as did the evening event discussed above, but at considerably lower speeds. The features at 01:57 and 02:13 UT (01.95-02.22 UT) are the best defined, and these are shown at $20 \mathrm{~s}$ resolution in Figs. 11 and 12. The structures evolve as they move, which must introduce some uncertainty into the velocity measurement, but the presence of an eastward drift is clearly seen in each case. Figure 13 plots the position of the point of maximum absorption within the field of view of the imaging riometer, as well as the maximum value. From this diagram the west-east velocities are estimated as $372 \mathrm{~m} / \mathrm{s}(22.3 \mathrm{~km} / \mathrm{min})$ and $750 \mathrm{~m} / \mathrm{s}$ $(45.0 \mathrm{~km} / \mathrm{min})$, respectively. In the south-north direction the maximum remains close to overhead during both the absorption peaks. For a short time in between them the maximum 


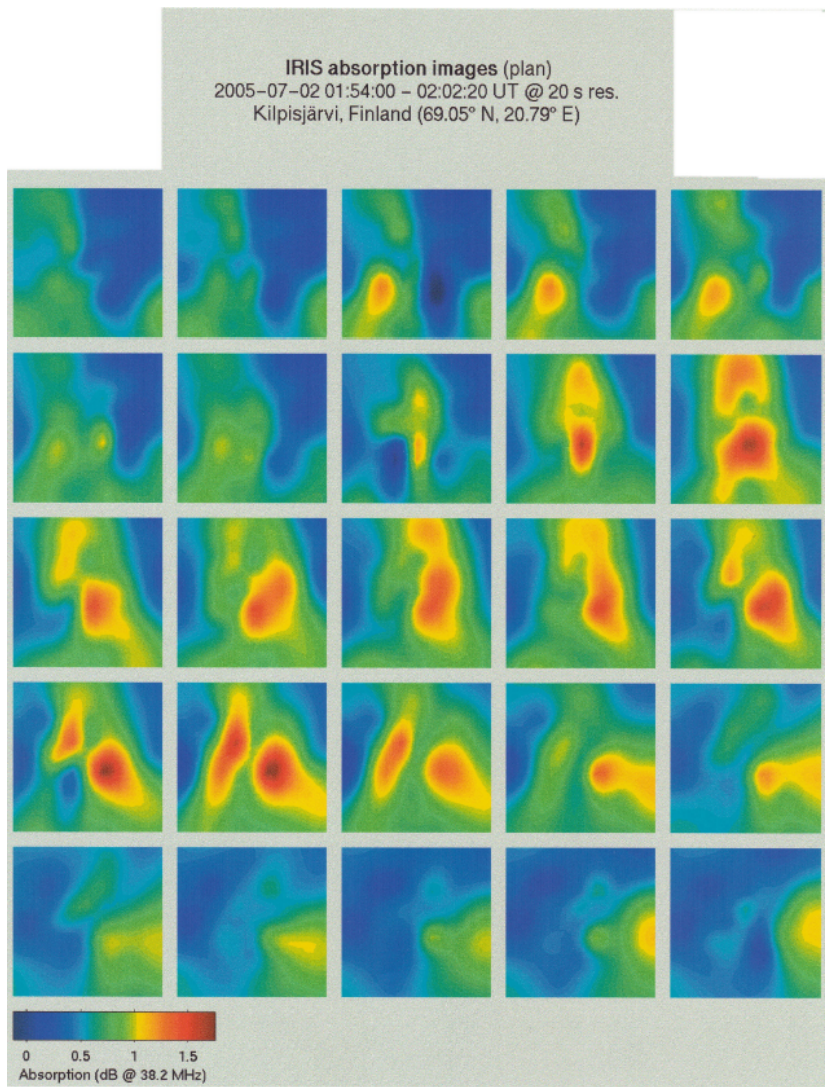

Fig. 11. The morning peak at 01:57 UT at $20 \mathrm{~s}$ resolution, over the period 01:54:00 to 02:02:20 UT. The field of view covers $240 \mathrm{~km}$ north-south and east-west, and is presented as if viewed from above.

appears to be off to the south-west and beyond the field of view.

Hargreaves and Berry (1976) investigated the motion of 42 absorption features in the morning sector using spaced widebeam riometers in Canada and the Antarctic, and obtained a median eastward velocity of $38 \mathrm{~km} / \mathrm{min}$ with quartiles at 20 and $55 \mathrm{~km} / \mathrm{min}$. In that study no structural detail could be observed, so it is interesting that the present results are consistent with the earlier ones, falling within the inter-quartile range. It is another confirmation that the observed motion cannot be due to the gradient-curvature drift of trapped electrons, the basic argument being that electrons of sufficient energy $(>50 \mathrm{keV})$ to cause the observed radio absorption would drift considerably faster than is observed. (The difference amounts to at least a factor of 2.5 in the simple theory, and to even more according to the modified theory of Bogott and Mozer, 1974).

\section{A POES overpass}

The satellite NOAA-16, travelling north to south at $850 \mathrm{~km}$ altitude, crossed the field of view of the Kilpisjärvi imag-

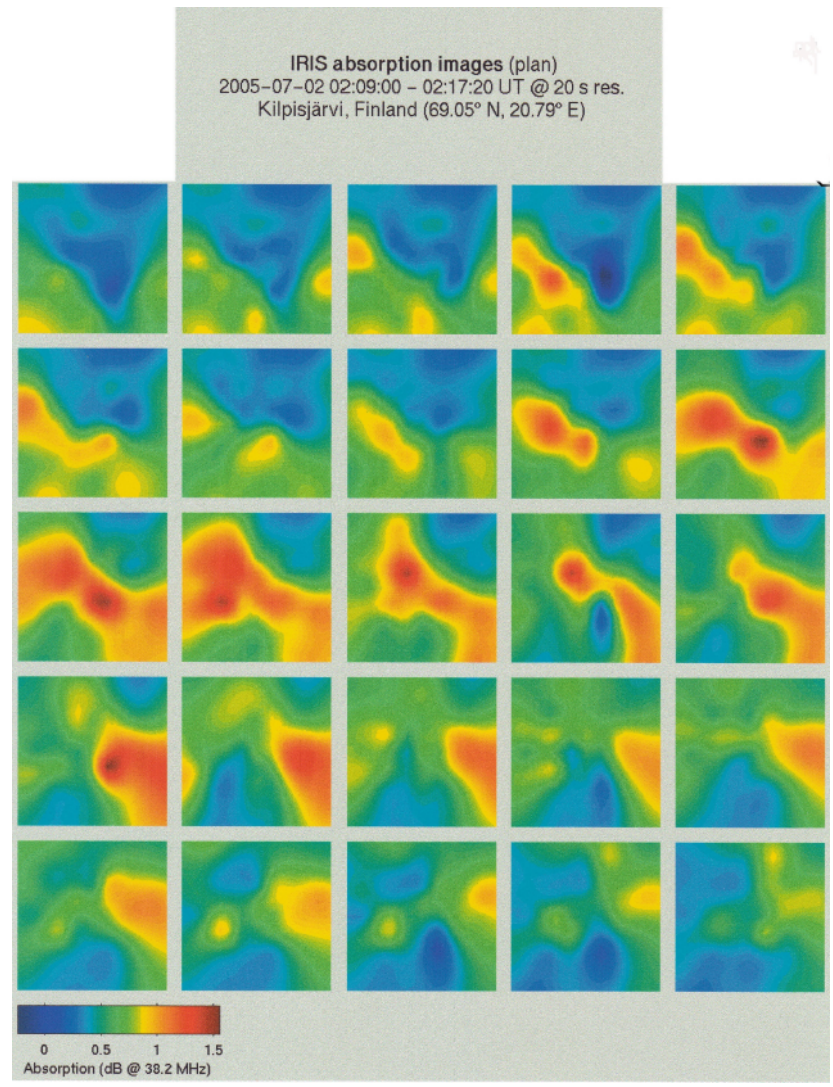

Fig. 12. As Fig. 11, but for the period 02:09:00 to 02:17:20 UT.
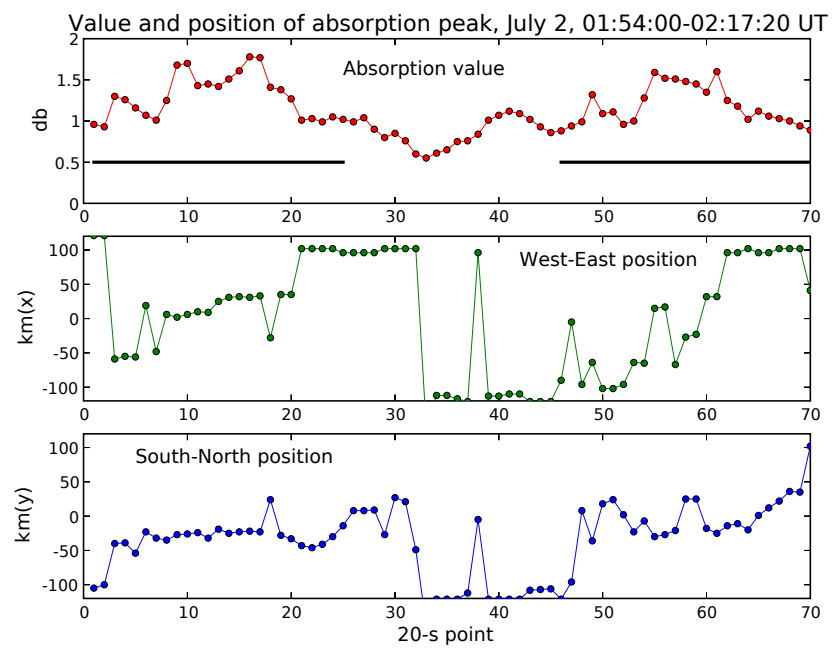

Fig. 13. Magnitude and position of the absorption maximum at $20 \mathrm{~s}$ interval from 01:54:00 to 02:17:20 UT. The horizontal bars mark the times covered in Figs. 11 and 12.

ing riometer towards the end of the morning event $(01: 00-$ 03:15 UT) on 2 July. The crossing took only $40-45 \mathrm{~s}$, and in Fig. 14 its footprint is shown against the spatial distribution of $38.2 \mathrm{MHz}$ radio absorption observed by the imaging 

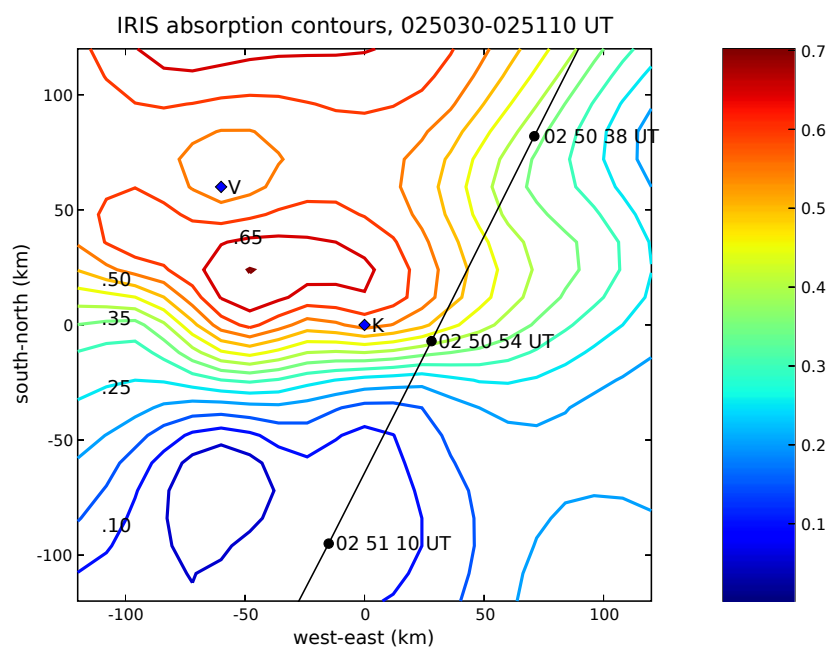

Fig. 14. Track of NOAA-16 across the distribution of $38.2 \mathrm{MHz}$ radiowave absorption derived from the imaging riometer at Kilpisjärvi (K). The position of the EISCAT VHF radar (V) is also shown.
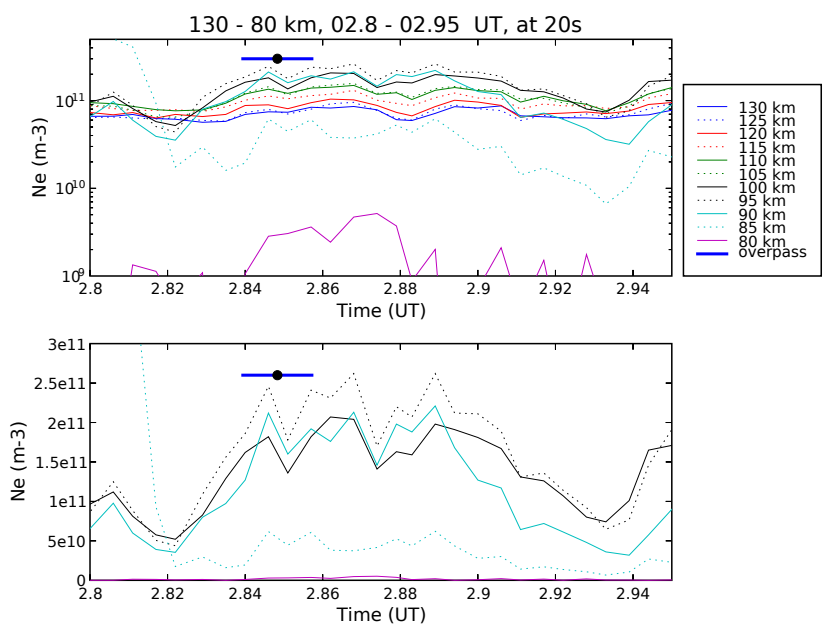

Fig. 15. Electron density variations from the VHF radar, 02:4802:57 UT. The time of the overpass and the central time of the IRIS map are marked.

riometer in the $40 \mathrm{~s}$ interval 02:50:30-02:51:10 UT (02.842$02.853 \mathrm{UT}$ ). The track passed about $30 \mathrm{~km}$ from the centre of the riometer system $(\mathrm{K})$ and $83 \mathrm{~km}$ from the EISCAT VHF beam $(\mathrm{V})$. It evidently traversed along and then across the edges of the absorption enhancement; the absorption patch was more uniform in the north-west quadrant of the field of view between Kilpisjärvi and the radar. (The satellite data were in fact mapped to the $\mathrm{E}$ region. A mapping to the $\mathrm{D}$ region would differ by only a few kilometers horizontally, a distance well within the beamwidth of the riometer.)

The radar observations (Fig. 15) indicate that the event was just reaching the maximum when the crossing occurred, and time variations during the pass were no more than about $30 \%$.

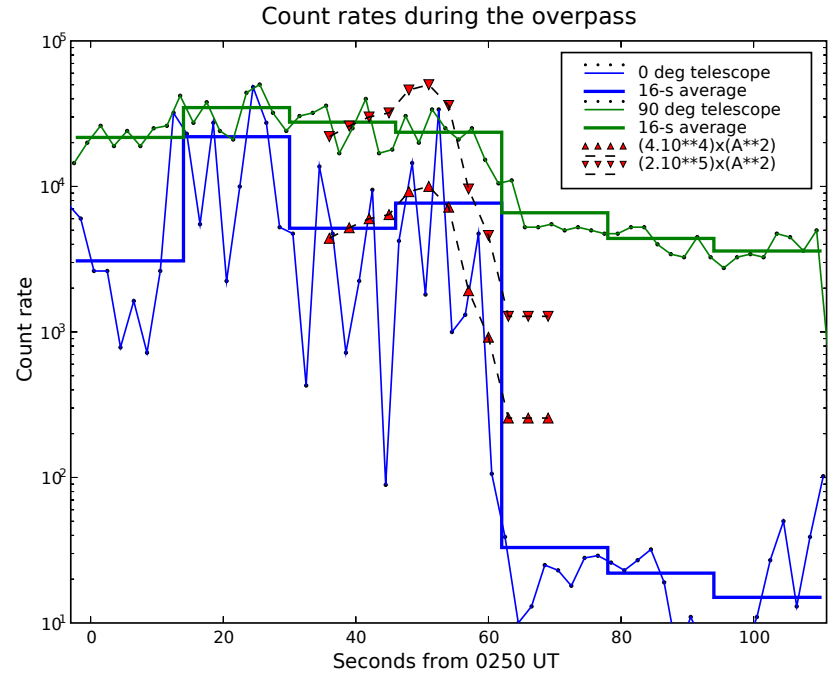

Fig. 16. Count rate of the $>30 \mathrm{keV}, 0^{\circ}$ and $90^{\circ}$ telescopes, during the overpass. For comparison, the triangles show "equivalent count rates", obtained by multiplying the square of the absorption estimated along the track at $3 \mathrm{~s}$ intervals by the factors $2.10^{5}$ and $4.10^{4}$ (see text).

The counting rates from the POES $0^{\circ}$ and $90^{\circ}$ detectors for electrons $>30 \mathrm{keV}$ are shown during the overpass in Fig. 16. Both $16 \mathrm{~s}$ and $1 \mathrm{~s}$ samples are shown for each. (The basic data are $1 \mathrm{~s}$ readings taken $2 \mathrm{~s}$ apart.) We note considerably greater variability in the $0^{\circ}$ (almost field-aligned) telescope, which seems to indicate large variations in the pitch-angle distribution of the $>30 \mathrm{keV}$ electrons. At time $60 \mathrm{~s}$, the flux in the $90^{\circ}$ telescope decreases by a factor of about 4 but that in the $0^{\circ}$ telescope by a factor of 200. This drop coincides quite closely with the edge of the absorption patch (Fig. 14). In considering this comparison it should be borne in mind that the POES satellite is at altitude $850 \mathrm{~km}$, that the absorption is assumed (though with supporting evidence) to be at $90 \mathrm{~km}$ altitude, and that the absorption map is based on only 49 data points, each covering some tens of $\mathrm{km}$. The spatial comparison is probably as good as can be expected in this situation.

Relations between the fluxes observed in the $0^{\circ}$ and $90^{\circ}$ telescopes will be discussed in a future communication (Birch et al., in preparation). We do not, however, expect to see the high variability of the flux in the $0^{\circ}$ telescope mirrored in the ionospheric electron densities because of the recombination time $\left(1 / \alpha \mathrm{N}_{e}\right.$, where $\alpha$ is the effective recombination coefficient and $\mathrm{N}_{e}$ the electron density), which is estimated to be in the range $8-23 \mathrm{~s}$ over the heights $85-105 \mathrm{~km}$ in the present instance.

Due to the geometric factor $\left(10^{-2} \mathrm{~cm}^{2} \mathrm{sr}\right)$, counting rates should be multiplied by 100 to obtain the particle flux. A count rate of $10^{4}$, for example, implies a flux of $10^{6}$ electrons $\mathrm{cm}^{-2} \mathrm{~s}^{-1} \mathrm{sr}^{-1}$. During the first part of the overpass (Figs. 14 and 16) the $90^{\circ}$ telescope measured a flux of about 
$2.5 \times 10^{6}$, while the $0^{\circ}$ telescope recorded a more variable flux averaging about $6 \times 10^{5}$. By conservation of the first invariant for trapped particles, all particles with pitch angle less than $57^{\circ}$ at $850 \mathrm{~km}$ have mirror points below $60 \mathrm{~km}$ (assuming a dipole field). We therefore have insufficient information for an accurate estimate of the total flux reaching the D region, but might suppose that somewhere between the $0^{\circ}$ and $90^{\circ}$ readings would be most appropriate.

The triangles on Fig. 16 are derived from the absorption interpolated to points along the satellite track during the satellite's overpass of the imaging riometer (Fig. 14). It is assumed that the electron density, and hence the absorption, is proportional to the square root of the incoming particle flux, and thus the values plotted on Fig. 16 are proportional to the absorption squared $\left(\mathrm{A}^{2}\right)$. Constants of proportionality $4.10^{4}$ and $2.10^{5}$ have been selected for comparability to the measured $0^{\circ}$ and $90^{\circ}$ fluxes exceeding $30 \mathrm{keV}$.

The satellite did not pass directly over the radar beam's intersection with the $\mathrm{D}$ region, and so we must extrapolate in order to compare the satellite data with results from the radar. At the point $\mathrm{V}$ on Fig. 14 the absorption was about $0.55 \mathrm{~dB}$. The corresponding count rates, according to the above relations between absorption and count rate, are $1.2 \times 10^{4}$ and $6.0 \times 10^{4}$, i.e. fluxes of $1.2 \times 10^{6}$ and $6.0 \times 10^{6} \mathrm{~cm}^{-2} \mathrm{~s}^{-1} \mathrm{sr}^{-1}$. Inverting the electron density profile over EISCAT for the minute beginning 02:50:24 UT gives a spectrum similar in shape to the later examples in Fig. 6b, there being two maxima (at 6 and $28 \mathrm{keV}$ ) with a marked dip at $17 \mathrm{keV}$. Summing the flux over the bands centred from 33.6 to $95.1 \mathrm{keV}$ (thereby covering 30.8 to $103.7 \mathrm{keV}$ between the band limits), then gives a total flux of $7.6 \times 10^{6}$ electrons $\mathrm{cm}^{-1} \mathrm{~s}^{-1} \mathrm{sr}^{-1}$, which, though somewhat larger than the value extrapolated from the POES data, is reasonable agreement considering the various assumptions and uncertainties involved.

The relations derived above between particle flux and absorption are consistent with those derived previously by Jelly et al. (1964) and by Parthasarathy et al. (1966) under different circumstances and using larger data sets.

\section{Summary and discussion}

D- and E-region activity has been investigated for a 24-h period using electron density measured by incoherent-scatter radar, cosmic-noise absorption observed with an imaging riometer, and energetic electron fluxes at $850 \mathrm{~km}$ detected on an orbiting satellite. Although it is not safe to generalise too far from a limited number of observations, auroral electron precipitation being a highly variable phenomenon, several interesting points have emerged.

1. Precipitation occurring in the afternoon period is soft, affecting the E region but not, observably, the D region. This helps to explain the well known afternoon mini- mum in the diurnal incidence of auroral absorption seen in riometer observations (Hargreaves, 1969).

2. The spectrum hardens and changes character postmidnight (in our case about 02:00 UT $\approx$ 04:20 MLT). In the present observations the change occurred within a short period of time. The double-peaked spectrum which appears in the morning period suggests the presence of two distinct particle populations.

3. There is general agreement between the $38.2 \mathrm{MHz}$ radiowave absorption estimated from the radar data and that measured directly with the imaging riometer, except that some short-duration features are more intense according to the radar. The explanation probably lies in the difference of beamwidth between the techniques if the features in question are smaller than the riometer beam in the D region. By the same token, we may infer that most of the absorption structures are larger than about $30 \mathrm{~km}$.

4. The typical height of the absorbing region is determined as $95 \mathrm{~km}$ pre-midnight, dropping to $90 \mathrm{~km}$ or even $85 \mathrm{~km}$ in the morning. Its thickness between the upper and lower quartiles is about $10 \mathrm{~km}$ in these measurements.

5. A spike event near magnetic midnight (21:35 UT $\approx 23: 55$ MLT) is interpreted from its motion as a pseudo-breakup. The form of the electron energy spectrum is essentially the same throughout the event (21:35-21:47 UT) but there is a large variation of intensity.

6. A morning event (01:20-02:35 UT $\approx 03: 40-04: 55$ MLT) shows eastward drift, but at a speed much slower than the gradient-curvature drift speed of electrons of the appropriate energy.

7. An overpass of a POES satellite shows a sharp reduction of $>30 \mathrm{keV}$ electron flux at the edge of an absorption patch in the morning sector. The electron spectrum deduced from the radar data is double peaked, and the total flux in the band $30-100 \mathrm{keV}$ is consistent with that registered on POES. It is noted that the flux observed in the $0^{\circ}$ detector is considerably smaller than the $90^{\circ}$ reading and much more variable in relative terms.

In recent years there have been a number of investigations of the causes and properties of D-region disturbances in the auroral regions using incoherent-scatter radar and riometers. The former technique has enabled the height profile of the electron density to be observed during energetic particle precipitation, from which the height and thickness of the absorbing layer can be calculated (Hargreaves, 1980; Ranta et al., 1985; Devlin et al., 1986; Hargreaves and Devlin, 1990) and the particle spectrum deduced (Devlin et al., 1986; Hargreaves and Devlin, 1990; Burns et al., 1990; Collis et al., 
1996; Collis and Hargreaves, 1997; Kirkwood et al., 2001). The riometer technique using spaced instruments, and more recently in the form of the imaging riometer (Browne et al., 1995), has improved our knowledge of the horizontal size and form of the absorption patches and of their horizontal motion over short (up to $\sim 200 \mathrm{~km}$ ) distances (Hargreaves, 1970; Hargreaves and Berry, 1976). Whether there exist structures smaller than the present IRIS beamwidth $(\sim 20 \mathrm{~km})$ has remained in doubt. The present work suggests that some do occur.

It is well known that during substorm activity the spectrum of precipitating energetic electrons changes with local time, tending to harden between midnight and noon. A reduction in the altitude of the absorbing layer is a natural consequence. The present results are consistent with previous estimates regarding height and thickness in general, though the gradual lowering of the height and the constancy of the thickness come out rather clearly in the present results. A double peak in the deduced dayside spectrum may be seen in some of the previous results, but it seems particularly clear in the present case. It is something of a surprise, however, that the character of the spectrum changes from the night to the day form within such a short period of time. The observed drift of the absorption patches is consistent with previous results regarding both direction and magnitude.

The agreement between the drop in particle flux recorded on the satellite and the edge of the absorption patch is to be expected (provided the appropriated particles are being observed). However, the greater variability of the precipitated flux relative to the trapped was not expected and is a feature worthy of further investigation.

On the broader scene this work is part of a study of the terrestrial consequences of events on the Sun and solar wind phenomena. It is well known that high-latitude radio absorption is statistically related to the speed of the solar wind, its sector structure and to the orientation of the interplanetary magnetic field (Hargreaves, 1966, 1996; Hargreaves and Cowley, 1967; Kavanagh et al., 2004). The activity reported here was associated with an increase in the solar wind speed, stemming from a solar coronal hole; there was no mass ejection (CME). Although terrestrial magnetic activity was enhanced between 15:00 UT and 03:00 UT the next day, significant auroral absorption did not begin until 21:30 UT. This absorption activity occurred during a period of enhancement in the solar wind whose onset, it is estimated, reached the magnetopause only 10 min before the onset of the night-time D-region event. The beginning of the velocity increase coincided with a southward turning of the IMF, and the delay is comparable to, though a little smaller than, delays between southward turnings of the IMF and changes of magnetospheric circulation pattern as reported by Hairston and Heelis (1995) during a three-day period in 1992. There were no obvious effects related to a series of sector boundary crossings which occurred between 08:40 and 14:40 UT on 1 July.
The prediction technique used to ensure the radar was operating by the time the disturbance arrived worked well, and has the potential to be a useful aid to efficient radar observations of solar-wind effects in the future.

Acknowledgements. We appreciate the assistance of the EISCAT group at the Rutherford Appleton Laboratory, Chilton, in setting up the experiment and in supplying us with the data. The imaging riometer at Kilpisjärvi is a joint operation between the University of Lancaster (Dept. of Communication Systems) and the Geophysical Observatory, Sodankylä, Finland. The data from the POES satellite were kindly supplied by D. S. Evans of the NOAA Space Environment Center, Boulder, Colorado.

Topical Editor M. Pinnock thanks D. S. Evans and M. Jarvis for their help in evaluating this paper.

\section{References}

Akasofu, S.-I.: The development of the auroral substorm, Planet. Space Sci., 12, 273-282, 1964.

Bogott, F. H. and Mozer, F. S.: Drifting energetic particle bunches observed on ATS 5, J. Geophys. Res., 79, 1825-1830, 1974.

Browne, S., Hargreaves, J. K., and Honory, B.: An imaging riometer for ionospheric studies, Electronics and Communication Engineering Journal, 7, 209-217, 1995.

Burns, C. J., Howarth, W. G., and Hargreaves, J. K.: Highresolution incoherent scatter radar measurements during electron precipitation events, J. Atmos. Terr. Phys., 52, 205-218, 1990.

Collis, P. N., Hargreaves, J. K., and White, G. P.: A localised corotating auroral absorption event observed near noon using imaging riometer and EISCAT, Ann. Geophys., 14, 1305-1316, 1996, http://www.ann-geophys.net/14/1305/1996/.

Collis, P. N. and Hargreaves, J. K.: Co-ordinated studies using imaging riometer and incoherent scatter radar, J. Atmos. SolarTerr. Phys., 59, 873-890, 1997.

Detrick, D. L. and Rosenberg, T. J.: A phased-array radiowave imager for studies of cosmic noise absorption, Radio Sci., 25, 325338, 1990.

Devlin, T., Hargreaves, J. K., and Collis, P. N.: EISCAT observations of the ionospheric $\mathrm{D}$ region during auroral radio absorption events, J. Atmos. Terr. Phys., 48, 795-805, 1986.

Evans, D. S. and Greer, M. S.: Polar Orbiting Environmental Satellite Space Environment Monitor - 2: Instrument descriptions and archive data documentation (version 1.4), NOAA Technical Memorandum, 2004.

Gledhill, J. A.: The effective recombination coefficient of electrons in the ionosphere between 50 and $150 \mathrm{~km}$, Radio Sci., 21, 399408, 1986.

Hairston, M. R. and Heelis, R. A.: Response time of the polar ionosphere convection pattern to changes in the north-south direction of the IMF, Geophys. Res. Lett., 22, 631-634, 1995.

Hargreaves, J. K.: On the variation of auroral radio absorption with geomagnetic activity, Planet. Space Sci., 14, 991-1006, 1966.

Hargreaves, J. K. and Cowley, F. C.: Studies of auroral radio absorption events at three magnetic latitudes. 1. Occurrence and statistical properties of the events, Planet. Space Sci., 15, 1571$1583,1967$. 
Hargreaves, J. K.: Auroral absorption of HF radio waves in the ionosphere - a review of results from the first decade of riometery, Proc. IEE 57, 1348-1373, 1969.

Hargreaves, J. K.: Conjugate and closely-spaced observations of auroral radio absorption - IV. The movement of simple features, Planet. Space Sci., 18, 1691-1705, 1970.

Hargreaves, J. K.: Dynamics of auroral absorption in the midnight sector - the movement of absorption peaks in relation to the substorm onset, Planet. Space Sci., 22, 1427-1441, 1974.

Hargreaves, J. K. and Berry, M. G.: The eastward movement of the structure of auroral radio absorption events in the morning sector, Ann. Geophys., 32, 401-406, 1976, http://www.ann-geophys.net/32/401/1976/.

Hargreaves, J. K.: D-region electron densities observed by incoherent-scatter radar during auroral-absorption spike events, J. Atmos. Terr. Phys., 42, 783-789, 1980.

Hargreaves, J. K. and Devlin, T.: Morning sector electron precipitation events observed by incoherent scatter radar, J. Atmos. Terr. Phys., 52, 193-203, 1990.

Hargreaves, J. K.: Substorm effects in the D region. Proc. Third International Conference on Substorms, Versailles, France, May 1996, ESA report SP-389, October 1996.

Hargreaves, J. K., Browne, S., Ranta, H., Ranta, A., Rosenberg, T. J., and Detrick, D. L.: A study of substorm-associated nightside spike events in auroral absorption using imaging riometers at South Pole and Kilpisjärvi, J. Atmos. Solar-Terrestrial Phys., 59, 853-872, 1997.

Hargreaves, J. K.: A new method of studying the relation between ionization rates and radio-wave absorption in polar-cap absorption events, Ann. Geophys., 23, 359-369, 2005,

http://www.ann-geophys.net/23/359/2005/.
Hargreaves, J. K. and Birch, M. J.: On the relations between proton influx and D-region electron densities during the polar-cap absorption event of 28-29 October 2004, Ann. Geophys., 23, 3267-3276, 2005, http://www.ann-geophys.net/23/3267/2005/.

Jelly, D. H., McDiarmid, I. B., and Burrows, J. R.: Correlation between intensities of auroral absorption and precipitated electrons, Can J. Phys., 42, 2411-2418, 1964.

Kavanagh, A. J., Kosch, M. J., Honary, F., Senior, A., Marple, S. R., Woodfield, E. E., and McCrea, I. W.: The statistical dependence of auroral absorption on geomagnetic and solar wind parameters, Ann. Geophys., 22, 877-887, 2004, http://www.ann-geophys.net/22/877/2004/.

Kirkwood, S., Osepian, A., and Smirnova, N.: Quantitative description of electron precipitation during auroral absorption events in the morning/noon local-time sector, J. Atmos. Solar-Terr. Phys., 63, 1907-1921, 2001.

Parthasarathy, R. and Berkey, F. T.: Multiple frequency investigation of radiowave absorption during the dawn breakup phase of auroras, Radio Sci., 69D, 415-421, 1965.

Parthasarathy, R., Berkey, F. T., and Venkatesan, D.: Auroral electron flux and its relation to broadbeam radiowave absorption, Planet. Space Sci., 14, 65-83, 1966.

Ranta, A., Ranta, H., Turunen, T., Silen, J., and Stauning, P.: High resolution observations of D region by EISCAT and their comparison to riometer measurements, Planet. Space Sci., 33, 583589, 1985. 